\title{
Determinants of Rural Household Food Security and Coping Up Mechanisms in the Case of Woliso Woreda Western Ethiopia
}

\author{
Tsegamariam Dula ${ }^{1 *}$ and Wakjira Berhanu ${ }^{2}$ \\ ${ }^{1}$ Department of agricultural economics, Ethiopia \\ ${ }^{2}$ Department of agricultural economics, Ethiopia
}

*Corresponding author: Tsegamariam Dula, Department of Agricultural Economics,

Received Date: November 27, 2018

Ethiopia.

Published Date: January 02, 2019

\begin{abstract}
Improving food security in Woliso woreda closely related with the elimination and reduction of poverty at woreda and individual level. Some of the rural household in Woliso woreda is suffer by food insecurity. Therefore, this study was investigated the determinants of food insecurity in the study area through using extended primary data.

The main objective of this study is to identify the main determinants of food insecurity rural household and its coping up mechanisms. The study regarding data requires collecting reliable information regarding food insecurity; data was collected from both primary and secondary data source. The primary data was collected from the rural household dwellers in Woliso rural kebeles through structured questionnaires and interview. Regarding secondary data was collected from different research papers that have do on food insecurity and also was collected from relevant institution such as Woliso woreda agriculture and rural development and Disaster prevention and preparedness commission office as well as published and un published data sources. A simple random sampling method will be employed to select the sampling units. The main significant of this study is creating awareness to the rural household and the woreda administrative leader about the determinants and the final result as well as the mechanism how to resolve the problem of food insecurity in the Woliso woreda rural household. In addition to these, the study is forward the concrete recommendation, which implies helping to improve food insecurity through basic policy implication and the participation of the rural household.
\end{abstract}

Keywords: Food insecurity; Food security; Calorie intake

\section{Introduction}

The food insecurity issues in Ethiopia should be view at different levels, such as at national, regional, household and intra-household levels. An attention should be given especially to food insecurity at the household level. Moreover, poor food distribution within household results in some member (usually women and children) to have inadequate intakes, thus there is a growing concern on the issue of intra-household food security [1].

In Ethiopia, minimizing food insecurity is closely relating with the elimination and reduction of poverty, hunger, and malnutrition. Minimizing food insecurity involves more than just increasing agricultural production (crop and livestock production [1].
According to World Bank Report in 2012, the main causes of food insecurity in Ethiopia include adverse climate change, declining land holding per household, drought, war, flood, lack of diversity of item, inefficient and lack of credit institution, administration problem, socio-economic problems; depletion of assets, absence of income and wide spread of illiteracy in rural population in Ethiopia.

The severity of food insecurity problem in Ethiopia varies from region to region depending up on natural resources availability. Drought is the only significant cause of chronic food insecurity in Ethiopia. The most affected regions by drought and food insecurity are mainly Tigray, Amhara, Afar, Somalia and some parts of Oromia 
regions, [2]. The major drought affected area of Oromia region is East Harerge and some woreda of Borena zones and the zones also food insecure [3].

Woliso woreda is one of the South West Shoa administrative zones. The accessibilities of food in some part of kebeles in the woreda is not adequate due to poor education level, family size, small landholding size, crop disease, poor information market and infrastructure, problem rainfall, Ceremonial expense, age of household and absence of credit service, etc. [3].

In fact, several studies have already conducted. Even though, there are still observe knowledge and methodology gaps that will need to be fill in. For instance, [4] studied cause and consequence of food insecurity in Woliso woreda by using descriptive analysis. The result shows up the decrement on the problem of food insecurity and identifies some cause result food insecurity in study area. However, the researcher did not incorporate other variables like lack of improved technology (fertilizer, herbicide, improved seed and pesticide) and sex of household that can effectively determine the problem of food insecurity among household. The descriptive analysis on this study is not sufficient so that we have to use both descriptive analysis and econometric analysis in order to investigate determinants of household food insecurity in Woliso Woreda.

\section{Objective of the study}

The general objective; to examine the determinants of household food insecurity and coping mechanisms among the farm households in Woliso woreda.

The specific objectives:

- To determine the level of food insecurity in the study area.

- To compare food secure and insecure household status

- To identify the determinants of rural household food security in the study area.

- To asses rural households coping mechanisms to household's food insecurity in the study area.

\section{Research Methods}

\section{Description of the study area}

The study will be conducted among households in Woliso woreda. It found in Southwest Shoa zone and far about $114 \mathrm{~km}$ from Addis Ababa. Its astronomical location is 32' north latitude and $37^{\circ} 58^{\prime}$ east longitudes with an elevation of 2063 meters above sea level. Woliso woreda is located in tropical climate zone and the climate condition is medium that the altitude of the land is waynadega. The relative location or visional position of the woreda has physically contacts with four woreda, namely Bacho, Goro, Wanchi, and Saden- Sodo woreda and one region namely SNNP. In terms of these woreda location, Woliso woreda is boarded in the North by Bacho, in the west by Wanchi, in the south west by SNNP, in the south by Goro and in the east by Sadden sodo woredas. The total population of Woliso woreda in rural and urban are 183391 from those, male and female are 91622 and 91769 respectively. In those, population $95 \%$ are living in rural area and economic activities of these woreda is mixed farming system. The total area of the woreda is approximately around 70238-hectare (Woliso woreda Agricultural and Land protection Bureau, 2018).

\section{Data type and source}

This study used both primary and secondary data. The primary data were collected from a sample of rural household's head through a structured questionnaire prepared for the study with closed ended and open-ended questions and interview. The secondary data will be collected from annual reports, documents, annual report of disaster prevention and preparedness commission office and economic journals.

\section{Sampling techniques and sample Size}

The target population for this study was all households of Woliso woreda. The total population of the households those exists in the woreda is 22,888 , and the woreda has 35 kebeles and 3 towns. From these kebeles,we want to select three kebeles. In this study, two stage random sampling procedure was used. At the first stage, 3 kebeles out of 35 kebeles were randomly selected. In the second stage, probability proportional to size sampling technique was employed to draw 115 sampled households from the selected sampled kebeles. The selected kebeles were namely, Foduu Goroo, Baddesa Qoricha, and Obii Koji.

Therefore, Foduu Goroo has total household of 657, Baddesa Qoricha has total household of 481 and Obii Koji has total household of 454 . In order to take a total sample size relevant to target study we were apply Yamane formula (1967) of $n=N / 1+N$ (e)2. In addition to this, we are going to use proportionate sampling that will be enable us in taking samples from each sub strata' which are to be selected from the target population.

$$
\begin{aligned}
& N=657+481+454 \text { where, } N=\text { the total number of households } \\
& N=1592 \text { e }=\text { the margin of error } \\
& \text { e }=9 \% \text { or } 0.09 \mathrm{n}=\text { the total sample size of households } \\
& \mathrm{n}=1592 \\
& 1+1592(0.09)^{2} \\
& \mathrm{n}=114.571 \sim 115
\end{aligned}
$$

Then we have to apply proportionate sampling to obtain how many respondents are selected from each stratum by using formulas: $\mathrm{nh}=\mathrm{nh}(\mathrm{Nh}) / \mathrm{N}$

Where: $\mathrm{nh}=$ Sample size for stratum $\mathrm{h}$

$\mathrm{Nh}$ is the numbers of households for stratum $\mathrm{h}$

$\mathrm{N}$ is the total numbers of households and $\mathrm{n}$ is the total sample size.

$$
\begin{aligned}
& \mathrm{nh} 1=\mathrm{n}(\mathrm{Nh} 1) / \mathrm{N} \text { nh2 }=\mathrm{n}(\mathrm{Nh} 2) / \mathrm{N} \text { nh3 }=\mathrm{n}(\mathrm{Nh} 3) / \mathrm{N} \\
& =115(657) / 1592=115(481) / 1592=115(454) / 1592 \\
& \mathrm{nh} 1=47.45 \sim 47 \mathrm{nh} 2=34.74 \sim 35 \mathrm{nh} 3=32.79 \sim 33
\end{aligned}
$$

So that, $n h 1=47, \mathrm{nh} 2=35$, and $n h 3=33$ are the sample size of the strata to the kebele, Foduu Goroo, Baddesa Qoricha, and Obii Koji respectively. 


\section{Method of data collection}

The primary data used for this study had collected from the representatives of the target population, sample, through questionnaires. These questionnaires were prepared in accordance with the objectives of the study and in a way that they were capture relevant data and information from the respondents. The structured interview was also being prepared for those cannot read due to different reasons. The study also augments by secondary data obtain from various sources (annual reports, documents, annual report of disaster prevention and preparedness commission office and economic journals).

\section{Method of data analysis}

The methods of analyzing data include both descriptive statistics and econometric analysis Descriptive statistic such as mean, standard deviation, frequency distribution, percentage and t-test, were used to study the demographic, socioeconomic and institution factor in relation to food insecurity status of households and its coping mechanisms in the study area. While an econometric tool, were used to analyze the determinants of household food insecurity in rural area.

\section{Econometric analysis}

Model specification: The data analysis, interpretation and discussion were depending on the dependent and explanatory variables that are listing in the following econometric model parts to analyze the determinants of household food insecurity.

The probit model: A probit model is used to estimate the dummy variable taking two values. These models are appropriate when the dependent variable is a binary variable. The response (dependent) variable of this study is dichotomous taking two values, 1 if the event occurs and 0 if it does not. In this study the dependent variable is dummy variable taking two values, 1 if a household food insecurity and 0 if household food security. In this regard, Probit model is one of the most, which estimate the probability of being in the household food insecurity dependent on some explanatory variables. Because of the fact that the binomial probit model is easier to estimate and simpler to interpret, this regression model is used in this study.

A probit model assume that there is a latent, unobserved continues variable $Y^{*}$ which can take all values in $(-\infty,+\infty)$ and that determines the values of $\mathrm{Y}$ and includes believable error term distribution as well as realistic probabilities. However, the underlining latent model can be specified as follows [4]:

$$
Y=\left\{1, Y^{*}>0 ; 0, Y^{*} \leq 0\right\} \text { and } Y^{*}=X^{\prime} \beta+\varepsilon
$$

However, Probit model is based on latent variable and why can be observed as an indicator for whether this latent variable is positive. In our study we specify that for

$$
\text { Y; } 1 \text { = Food insecurity, } 0 \text { = Food security }
$$

$\mathrm{X}$ stands for vector of explanatory variables

$\beta$ stands for coefficients, and

$\varepsilon$ stands for random errors.
In our study we use marginal effect for both continuous and dummy variables. From probit model we estimate marginal effect of " $\mathrm{i}$ " variables as the effect of a unit change of this "i" variable on the probability $\mathrm{P}(\mathrm{Y}=1 \| \mathrm{X}=\mathrm{x})$ given that all other variables are constant.

In this study we use the above equation to compute predicted probability for household to become food insecure when Food insecurity is equal to one (1) and food security if equal to zero (0).

\section{Description of variable}

Description of dependent variable

a. Food insecurity: Food insecurity is the inability to provide enough food for a health and active lifestyle. Food insecurity is a measured as a household-level concept that refers to uncertain, insufficient, or unacceptable availability of utilization of food.

Description of the explanatory variable:

a. Sex of the household respondent: Sex is the categories of households who are male and female. A dummy variable taking two values, 0 if female and 1 otherwise.

b. Marital status of household: It determines the household of food insecurity status. The study by Adekoyo in Oyo state of Nageria in 2009 found that married household to food insecure where unmarried household were founding to be food secured. Moreover, the married household according to [5], were highly positioned to be found insecure. A dummy variable taking two values, 0 if umarried, 1 if married.

c. Ceremonial expense of the household respondent: Ceremonial expense refers to the total money of household spends on wedding and other traditional social status (taskar) and measured in money. Ceremonial expense of the household is continuous.

d. Land size: Land size is referring to the total farmland owned by the household and measured in hectare. Land size of household is continuous.

e. Livestock ownership measured in (TLU): It was treated as a continuous variable. Livestock contribute to household's economy in different ways, e.g. as a source of pulling power, source cash income, source of supplementary food, and means of transport. Besides, livestock are considering as the means of security and means cop during crop failure and another climate Haile et al. [6].

f. Dependence ratio: It is treated as a continuous variable and measure as the total household size divided by the number of individual working to support the household. Due to the scarcity of resource and increase in household size especial the nonworking members put pressure on consumption than production. An increase in the number of non-working member of household or dependence ratio increase in food insecurity in the level of household.

g. Household head education: Education is referring to promoting awareness on the possible advantages modernizing agriculture though technological inputs and diversifying 
household incomes, which in turn enhance household supply. A dummy variable taking two values, 0 if education of household is illiterate, 1 if literate.

h. Pesticide use: Pesticide can save (preventing) farmers from crop losses by insects and other pests. Pre and postharvest crop losses caused by insect (pests), diseases and weeds and storage pest have contributed much to the decline of agricultural production that tends to food insecurity in study area. A dummy variable taking two values, 1 if pesticide used and 0 otherwise.

\section{Hypothesis}

The Sex may seem insignificant but female household headed is positive relationship with food insecurity than males. Marital status is the most indicators that determine the level of food insecurity and food security. The households headed those are single have more power to fight food shortage than the rest. Therefore, marital status those married is positive relationship with food insecurity. Ceremonial expense and dependence ratio are significant (positive); because they have direct relationship with food insecurity, but the land size has the insignificant relationship with food insecurity, an increase in land size; the productivity of food is increase. Household head Education are negative relationship, because they are increase leads to decrease food insecurity and they affect it adversely. Livestock and pesticide use are significant and negative relationship, because they are increase leads to decrease food insecurity and they affect it adversely.

Description of variables and expected sign: The following table gives the variables, which are incorporate in the model with expected signs.

\section{Results and Discussions}

This chapter is depending on data analysis, presentation and interpretation. It provides detail explanations of the determinants of food insecurity, level of food insecurity and the households of coping mechanism of food insecurity in the study area.

\section{Demographic and Socio-Economic Characteristics of the Sampled Households}

Age, sex and family size are important demographic characteristics that could affect the food insecurity status at the household level. The oldest age was participated in this study and they are most suffering by food insecurity, because the oldest age or the retired age is not able work more hours as compared to the adult age. The adult age can work more hours, and they are more producers rather than the oldest age.

Nevertheless, the oldest age covered the greatest number of food insecure due to low level of productive age and high level of old and youth level of age. As the result, the productive age cannot cover or feed to the all households. Therefore, age of households was determinant of food insecurity in the study area.

According to the above Table 1 shows, from the out of the total sample household, the mean (average) age of household is, 43.86 with the maximum (largest) of 80 and a minimum (smallest) of 23 . Form the total sample households, the female household headed are $18.26 \%$ (21) and male head are $81.74 \%$ (94).

Family size of the household also has a direct impact on the household's food insecurity. According to [7] labor input availability for productivity and pressure on consumption is describing by household family size. That means household headed have more family size creates more pressure on consumption than the production it contributes. From the total sample household, the mean of family size was 4.6 with the 9 and 2 a maximum and minimum respectively.

Education, and marital status of sample households: Education, and marital status are also identified the level of food unsecured among the household. Marital status is the most indicators that determine the level of food unsecured and food secured. As the above Table 1 indicates, from the total sample households headed those are unmarried, married, are 4.35\% (5), 95.65\% (110) respectively. However, from the total of household headed those categorized in to food unsecured and secured are $25.22 \%$, (29) 74.78\%, (86) illiterate and literate respectively. Education is important to increase the quality of live standard among the households.

Ceremonial expense: According to the above Table 1 shows, ceremony expense are determine the level of food secured and unsecured at households level in the study area. The average (mean) money expense is 781.70 with the maximum (largest) of 1700 and a minimum (smallest) of 400 .

Table 1: Expected sign of variable.

\begin{tabular}{|c|c|c|c|c|c|}
\hline S. No. & Variables & Description of Variables & Continuous/Dummy & Values & Expected Sign \\
\hline 1 & Food insecurity & $\begin{array}{l}\text { Food insecurity of the house } \\
\text { hold }\end{array}$ & Dummy & Calorie intake & \\
\hline \multirow{2}{*}{2} & \multirow{2}{*}{ Sex } & \multirow{2}{*}{ Sex of house hold } & \multirow{2}{*}{ Dummy } & $1=$ Male & + for female \\
\hline & & & & $0=$ Female & \\
\hline \multirow{2}{*}{3} & \multirow{2}{*}{ Marital status } & \multirow{2}{*}{ Marital status of household } & \multirow{2}{*}{ Dummy } & 1=Married & -for Unmarried \\
\hline & & & & $0=$ Unmarried & \\
\hline \multirow{2}{*}{4} & \multirow{2}{*}{ Household head education } & \multirow{2}{*}{ Household head education } & \multirow{2}{*}{ Dummy } & $1=$ literate & -for literate \\
\hline & & & & $0=$ illiterate & \\
\hline 5 & Land size & Land size & Continuous & Hectares & - \\
\hline
\end{tabular}




\begin{tabular}{|c|c|c|c|c|c|}
\hline 6 & Ceremony expense & ceremonial expense & Continuous & Money & + \\
\hline 7 & Livestock & Livestock ownership & Continuous & TLU \\
\hline 8 & Dependency ratio & Dependence ratio & Continuous & Child+old/adult*100 & + \\
\hline 9 & Pesticide use & Pesticide use & Dummy & $1=$ Use & -for user \\
\cline { 3 - 6 } & & & & $0=$ Not \\
\hline
\end{tabular}

The expenditure beyond ability for purpose of wedding and taskar are decreasing the amount of cereal crop, which used for consumption. The decline of crop that used food consumption tends to food insecure so; food insecurity and ceremony practice have positive relationship. Therefore, the households headed practice ceremony is more food secured than households headed not practice.

Fertilizer use: According to the above Table 1 shows, fertilizer use is determining the level of food secured and unsecured at households' level in the study area. The mean of fertilizer use is 1.55 quintal with the maximum of 4 quintal and a minimum 0 . Calorie intake and food insecurity are influenced by use of fertilizer as it more successful agricultural production (Haile et al. (2005). Using low amount of fertilizers was the main factor for low productiveness of the farmer. When come to the reality within the study area the land farm of our respondents is very poor fertility thus, poor fertile soil needs to get the fertilizers to give high yields. Therefore, fertilizer use and food insecurity have negative relationship.

Dependency ratio: Dependency ratio is the proportion of the total number of young ( $<15$ years old) and old age group ( $>65$ years old) members to the total number of active age groups (15-65). Thus, dependency ratio was a significant factor to differentiate food secure from food insecure groups.

Production of crops and asset ownership of sample households: According to the above Table 2 shows, production of crop, inset and land are determining the level of food secured and unsecured at households level in the study area. The land in hectare has 1.7 mean with the maximum of 3 hectare and a minimum 0 from the total household land owned and the average number of livestock 3 with the maximum of 5 and a minimum of 0 those the total sample of households owned in the study area.

Table 2: Characteristics of sample respondent.

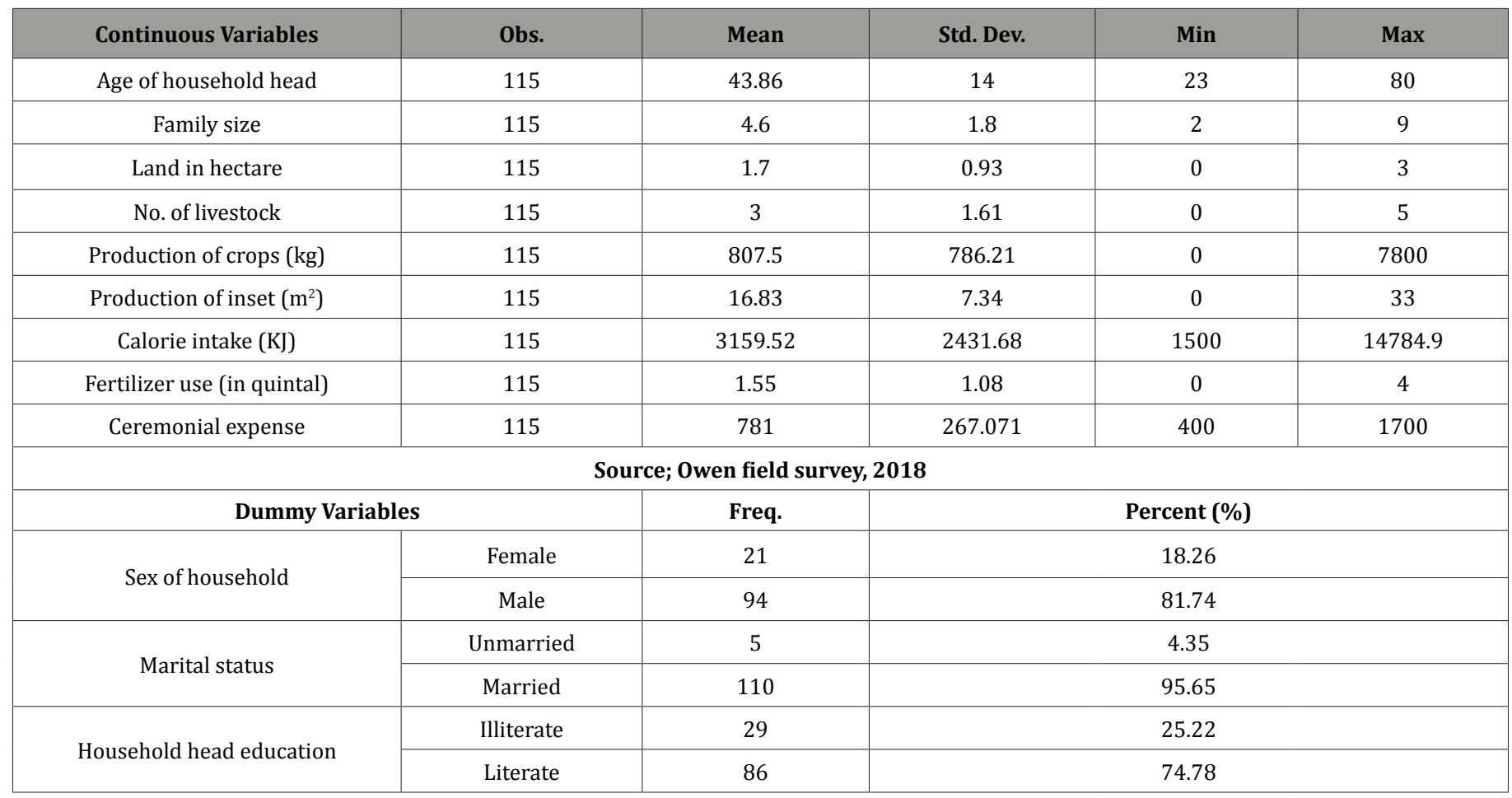

The production of inset is very important for consumption in our study area, because majority of the population rely on its. The inset production mean (average) on the area $(\mathrm{m} 2)$ of 16.83 with the maximum of 33 and minimum 0 area of meter square. Calorie intake is the measurement cutoff household food insecurity and food security. Out of the sample household the mean, (average) of calorie intake 3159.52 with a 14784.9 and 1500 the maximum and minimum respectively.

\section{Food security status of sample households}

For examining the food security status of sample households, calorie acquisition was taken as an indicator, for computing calorie acquisition; methodology suggested by [8] was followed. The total quantities of product, which used for meals prepared for the sample households that known in a monthly such as flour of teff, wheat,etc and that brought from the market within the seven days 
like vegetable were computed and converted into calorie terms and divided by thirty (30) and seven (7) respectively. The food and drink, which used daily like coffee, milk, bread etc. had converted into calorie terms and added on them.

Based on the summation of total calories for monthly, seven days and daily, average calorie acquisition per day for each household was computed. Finally, calorie per day per adult equivalent was

Table 3: Comparison of food insecurity by sex of household. computing by dividing the average per day calorie acquisition by adult equivalent units of the family. As per standard sets by the Ethiopian government, $2200 \mathrm{kcal}$ per adult equivalent per day was taken as a cutoff value between food secure and insecure households. The result indicates that 86 (74.8 percent) and 29 (25.2 percent) households were food secure and food insecure respectively in study area (Table 3 ).

\begin{tabular}{|c|c|c|c|c|c|c|}
\hline \multirow{2}{*}{ Sex } & \multicolumn{2}{|c|}{ Food Secured } & \multicolumn{2}{|c|}{ Food Insecure } & \multicolumn{2}{l|}{} \\
\cline { 2 - 7 } & Frequency & Percent & Frequency & Percent & Total & t-test \\
\hline Female & 9 & $43 \%$ & 12 & $57 \%$ & 21 & - \\
\hline Male & 77 & $82 \%$ & 17 & $25 \%$ & 115 & - \\
\hline Total & 86 & $75 \%$ & 29 & $3.94 * * *$ \\
\hline
\end{tabular}

Comparison of food insecurity between different groups: The comparison of food insecurity used to estimate the level of food unsecured and secured among the household between different groups in study area. On other way, they comparison the effects of variable on food insecurity that estimate in chapter three.

Comparison of food insecurity by sex of household: Table 4 above shows that, male-headed households are more food secured than female-headed household. Of female-headed households, $43 \%$ are food secured and $57 \%$ are food unsecured. However, of male-headed households, $82 \%$ are food secured and 18\% are food unsecured. The percent difference of food insecurity between male and female-headed households is $39 \%$, which is significant at $1 \%$.

Table 4: Comparison of food insecurity by household head education.

\begin{tabular}{|c|c|c|c|c|c|c|}
\hline \multirow{2}{*}{ Household Head Education } & \multicolumn{2}{|c|}{ Food Secured } & \multicolumn{2}{c|}{ Food Unsecured } & \multirow{2}{*}{ Total } & \multirow{2}{*}{ Percent } \\
\cline { 2 - 7 } & Frequency & Percent & Frequency & Percent & 29 & $25 \%$ \\
\hline Illiterate & 4 & $14 \%$ & 25 & $86 \%$ & 86 & $95 \%$ \\
\hline Literate & 82 & $95 \%$ & 4 & $5 \%$ & 115 & $100 \%$ \\
\hline Total & 86 & $75 \%$ & 29 & $25 \%$ & 29 \\
\hline
\end{tabular}

The male is directly engaged in livestock production, he contributes more labor than female. Labor factor plays a great role in rural areas. Hence, male-headed households are in a better position to pull labor force than the female-headed ones. Moreover, with regard to farming experience, it is assuming that males are better than the female. [9] reported that the sex of the household head has statistically significant positive effect on food insecurity when females head a household.

Comparison of food insecurity by household head education: Table 5 shows that, the educational status of household heads between food secure and insecure households. Of the total illiterate households, $86 \%$ were food insecure, while only $14 \%$ of them were food secure. Household heads who are literate, $95 \%$ and $5 \%$ were food secure and food unsecured respectively. Education level play the major role in minimizing the food insecurity and in improvement of living quality; by increase the knowledge of how to use the new technology, how to use the improved seed, chemical fertilizer, family planning, improve management of resources.

Some number of the households were illiterate, and they are also more food unsecured so, education level of household is negative relation with food insecurity.

Table 5: Comparison of food insecurity by marital status of household.

\begin{tabular}{|c|c|c|c|c|c|c|c|}
\hline \multirow{2}{*}{ Improved Seed } & \multicolumn{2}{|c|}{ Food Secured } & \multicolumn{2}{|c|}{ Food Unsecured } & \multirow{2}{*}{ Total } & \multirow{2}{*}{$\begin{array}{l}\text { Difference in percent of } \\
\text { food unsecured hhs }\end{array}$} & \multirow{2}{*}{ t-test } \\
\hline & Frequency & Percent & Frequency & Percent & & & \\
\hline Nonuse & 7 & $19 \%$ & 29 & $81 \%$ & 36 & - & - \\
\hline Use & 79 & $100 \%$ & 0 & $0 \%$ & 79 & $80 \%$ & $17.93^{* * *}$ \\
\hline Total & 86 & $75 \%$ & 29 & $25 \%$ & 115 & - & - \\
\hline
\end{tabular}

Comparison of food insecurity by marital status of household: According to Table 6 above shows that, of households headed those marital status is single $100 \%$ are food secured and $0 \%$ is food unsecured. However, of households headed those are married, $75 \%$ are food secured and 25\% are food unsecured in reality households headed those are unmarried have more power to fight food shortage than the rest. Because the households headed those are divorced distributed the owned property, reduced asset by accused each other and adopt bad habit like, drink and smoking. Therefore, the households headed those are unmarried have negative relationship with food insecurity. 
Table 6: Comparison of food insecurity by pesticide use of household

\begin{tabular}{|c|c|c|c|c|c|c|c|}
\hline \multirow{2}{*}{ Improved Seed } & \multicolumn{2}{|c|}{ Food Secured } & \multicolumn{2}{c|}{ Food Unsecured } & \multirow{2}{*}{ Total } & \multicolumn{2}{c|}{$\begin{array}{c}\text { Difference in percent of } \\
\text { food unsecured hhs }\end{array}$} \\
\cline { 2 - 8 } & Frequency & Percent & Frequency & Percent & & - & - \\
\hline Nonuse & 7 & $19 \%$ & 29 & $81 \%$ & 36 & $79 \%$ & $17.93^{* * *}$ \\
\hline Use & 79 & $100 \%$ & 0 & $0 \%$ & 79 & - & - \\
\hline Total & 86 & $75 \%$ & 29 & $25 \%$ & 115 & & - \\
\hline
\end{tabular}

Comparison of food insecurity by improved seed: Table

7 above shows that, of households headed not used improved seed, $19 \%$ are food secured and $81 \%$ are food unsecured. Even though, of households headed used improved seed, $100 \%$ are food secured and $0 \%$ is food unsecured. The percent difference of food unsecured between household headed whose used improved seeds and not used is $80 \%$, which is significant at $1 \%$. As the result the households headed used improved seed are more food secured

Table 7: Comparison of food insecurity by pesticide use of household.

\begin{tabular}{|c|c|c|c|c|c|c|c|}
\hline \multirow{2}{*}{ Pesticide Use } & \multicolumn{2}{|c|}{ Food Secured } & \multicolumn{2}{|c|}{ Food Unsecured } & \multirow{2}{*}{ Total } & \multirow{2}{*}{$\begin{array}{l}\text { Difference in percent of } \\
\text { food unsecured hhs }\end{array}$} & \multirow{2}{*}{ t-test } \\
\hline & Frequency & Percent & Frequency & Percent & & & \\
\hline Nonuse & 12 & $31 \%$ & 27 & $69 \%$ & 39 & - & - \\
\hline Use & 74 & $97 \%$ & 2 & $3 \%$ & 76 & $66 \%$ & $11.22^{* * *}$ \\
\hline Total & 86 & $75 \%$ & 29 & $25 \%$ & 115 & - & - \\
\hline
\end{tabular}

Comparison of food insecurity by pesticide use: According to the above Table 8 shows that, households headed used pesticide are more food secured than households headed not used. Of households headed not used pesticide, $31 \%$ are food secured and $69 \%$ are food unsecured. Although, of households headed used pesticide, $97 \%$ are food secured and $3 \%$ is food unsecured. The percent difference of food unsecured between household headed whose, used pesticides and not used is $66 \%$, which is significant at $1 \%$.

Table 8: Comparison of food insecurity by herbicide use of household.

\begin{tabular}{|c|c|c|c|c|c|c|c|}
\hline \multirow{2}{*}{ Herbicide Use } & \multicolumn{2}{|c|}{ Food Secured } & \multicolumn{2}{c|}{ Food Unsecured } & Total & $\begin{array}{c}\text { Difference in percent of } \\
\text { food unsecured hhs }\end{array}$ & t-test \\
\cline { 2 - 7 } & Frequency & Percent & Frequency & Percent & & - \\
\hline Nonuse & 5 & $15 \%$ & 29 & $85 \%$ & 34 & - \\
\hline Use & 81 & $100 \%$ & 0 & $0 \%$ & 81 & $21.48 * * *$ \\
\hline Total & 86 & $75 \%$ & 29 & $25 \%$ & 115 & - \\
\hline
\end{tabular}

Comparison of food insecurity by herbicide use: Table 9 above shows that, households headed used herbicide are more food secured than households headed not used. Of households headed not used herbicide, $15 \%$ are food secured and $85 \%$ are than households headed not used. The use of improved seed has expected to give better yield than local seed per unit area. As the result, household using improved seed on their farmland have more potential of producing more crop which helps to reduce risk of food insecurity. [5] conclude in their study that household not using improved seed have more probability of being food unsecured than other. As the result, use of improved seed is negatively relation with food insecurity.
Pre and post-harvest crop losses caused by insect (pests), diseases and weeds and storage pest have contributed much to the decline of agricultural production that tends to food unsecured in study area. The study area is some suffers by insect (pest) and weeds. Concerning post-harvest loss production, caused by storage pests (such as weevil) poor threshing and storage facility loss crop production in the study area. Therefore, decline of production by pest leads to food unsecured. food unsecured. Although, of households headed used herbicide, $100 \%$ are food secured and $0 \%$ is food unsecured. The percent difference of food unsecured between household headed whose, used herbicides and not used is $85 \%$, which is significant at $1 \%$.

Table 9: Comparison of food insecurity by credit access of household.

\begin{tabular}{|c|c|c|c|c|c|c|c|}
\hline \multirow{2}{*}{ Credit Access } & \multicolumn{2}{|c|}{ Food Secured } & \multicolumn{2}{c|}{ Food Unsecured } & \multirow{2}{*}{ Total } & $\begin{array}{c}\text { Difference in Percent of Food } \\
\text { Unsecured hhs }\end{array}$ \\
\cline { 2 - 7 } & Frequency & Percent & Frequency & Percent & t-test \\
\hline No access & 11 & $29 \%$ & 27 & $71 \%$ & 38 & - & $11.74^{* * *}$ \\
\hline Yes Access & 75 & $97 \%$ & 2 & $3 \%$ & 77 & $68 \%$ & - \\
\hline Total & 86 & $75 \%$ & 29 & $25 \%$ & 115 & \\
\hline
\end{tabular}

Herbicide is the most important to increase the production of the farmer. Herbicide is the chemical that used to kill the weeds in 
Comparison of food insecurity by credit access: According to Table 10 above shows that, of households headed not get access credit, $29 \%$ are food secured and $71 \%$ are food unsecured. However of households headed get access credit, $97 \%$ are food secured and
$3 \%$ is food unsecured. The percent difference of food insecurity between household headed whose access credit and not is $68 \%$, which is significant at $1 \%$.

Table 10: Summary results of Probit regression model for the determinants of rural household food security.

\begin{tabular}{|c|c|c|c|c|c|}
\hline Food Insecurity & Coef. & Std. Err. & Z & P>z & Marginal effects (dy/dx) \\
\hline Sex & -0.0717735 & 0.503222 & -0.14 & 0.887 & -0.0093444 \\
\hline Land size & -0.708384 & 0.4598969 & -1.54 & 0.123 & -0.0922261 \\
\hline Livestock & $-.3470242^{* *}$ & 0.1581604 & -2.19 & 0.028 & -0.0451799 \\
\hline Pesticide & $-1.195416^{* *}$ & 0.554524 & -2.16 & 0.031 & -0.155634 \\
\hline Marital Status & 0.1350642 & 0.4143672 & 0.33 & 0.744 & 0.0175843 \\
\hline Education & $-1.360844^{* *}$ & 0.5821145 & -2.34 & 0.019 & -0.1771714 \\
\hline Ceremonial expense & $-001846^{* *}$ & 0.0008201 & 2.25 & 0.024 & 0.0002403 \\
\hline Dependency ratio & $1.457972^{* * *}$ & 0.4791706 & 3.04 & 0.002 & 0.1898166 \\
\hline _cons & -0.3013534 & 1.161004 & -0.26 & 0.795 & - \\
\hline
\end{tabular}

Credit institutions like Microfinance Institution play a great contribution to reduction and minimization of poverty and food insecurity; it played a significant role in the rural households through provision of credit with fair and low interest rate as well as with appropriate collateral.

When come to the reality within the study area, the provision of credit service by the credit institutions was very limited and insufficient. Because there are, several reasons such as limited access of credit institution in the study area, the existing institution also setting higher interest rate, rural household have not relevant collateral and the rural households have low interest to borrow a loan. Therefore, the households headed get access credit is more food secured than households headed not access credit.

\section{Econometric Analysis}

The economic analysis of this paper mainly deals with the analysis; interpretation and discussion were based on the dependent and explanatory variables that were used in econometric model parts to analyze the determinants of household food insecurity. To identify determinants of food insecurity among hypothesized explanatory variables that are influence on rural households, the binary probit model was estimated using a statistical package known as STATA version 12. Different types of goodness fit confirmed that the model fits the data well. The values of chi-square test show the overall goodness of fit of the model is significant at $1 \%$ level. Another measure of goodness fit in probit regression analysis is measured by count $\mathrm{R} 2$, which works on the principle that if the predicted probability of the event is greater than 0.5 , the event will occur otherwise the event will not occur [10]. The overall prediction of the model is found to be $65.79 \%$, which is greater than 0.5 .

From the econometric model result, the sex, ceremonial expense, dependency ratio, signs are expected to be positive; because they have direct relationship with food insecurity but the signs of marital, land size, education, livestock and pesticide use are expected to be negative signs, because they have inverse relationship with food insecurity and they affect it adversely. But marital status, education, land size and sex are insignificance.
The contribution of each individual variable to the explanation of the determinants of household food insecurity, in conjunction with other independent variable using the probit regression analysis, shows that, five variables, among the 8 explanatory variable that were included in the model, were found to be statistically significant at various probability levels [11-13]. Ceremonial expense, educational level, livestock, dependency ratio and pesticide use were found important factors that influence household food insecurity in the study area. The remaining three variables were not statistically significant at the conventional levels of significance.

Livestock: Maintaining livestock production was found an important livelihood activity for the majority of the sample households. As expected, the relationship between livestock holding and household food insecurity status was negative and statistically significant at $5 \%$ probability level. The increase livestock decrease the predicted probability of the household being food insecure [1416]. The probability of food insecurity decreases by $4.51 \%$ as the numbers of livestock increases by one unit, holding all other factors constant.

Pesticide use: Pesticide used was a significant determinant of food insecurity at $5 \%$ probability level. As the result the relationship between pesticide use and food insecurity was negative [17]. As compared to pesticide user with nonuser the probability of food insecurity for the user is lower by $15.56 \%$, holding another variable remain constant.

Education: The household head education was a significant determinant of food insecurity at $5 \%$ probability level. As the result the relationship between education and food, insecurity was negative. As compared to illiterate with literate, the probability of food insecurity for literate is lower by $17.71 \%$, holding another variable remain constant.

Ceremonial Expense: The of model show that ceremonial expense was a significant determinant of food insecurity at 5\% probability level. As expected, the relationship between ceremony expense and household food insecurity was positive, that is the 
large ceremony expense is, the more the probability of a household to be food insecure. The increase ceremony expense increases the predicted probability of the household being food insecure [18-20]. The probability of food insecurity increases by $0.024 \%$ if the ceremony expenses increases by one unit, holding all other factors constant. As the expense for different holidays, weeding and different ceremonies increase, the expense for consumption of food item for the households (family members) decrease. As the result, the high expense for different ceremonies leads to food shortage for consumption and suffers by food insecure.

Dependency ratio (DR): The likelihood estimate revealed that dependency ratio was a significant determinant of food insecurity at $1 \%$ probability level of significance [21]. As hypothesized, the relationship between dependency ratio and household food insecurity was positive. The increase dependency ratio increases the predicted probability of the household being food insecure.

The probability of food insecurity increases by $18.98 \%$ as the dependency ratio increases by one unit, holding all factors constant.

\section{The households coping mechanism to challenge food insecurity}

The rural household of the study area were used various strategies to cop up with food insecurity [22,23]. Among those mechanisms obtaining loan from either relatives or neighbors, sales of domestic animals, contracting own lands and storage of cereals and grains.

As indicated in the Table 11 above 4.35\% (5) respondents cop up the food insecurity by getting loan from friends and relatives, $11.30 \%$ (13) respondents cop with the selling of animals, $2.61 \%$ (3) respondents use the copping mechanism by renting out their land, and $8.7 \%$ (8) respondents were copping mechanism by getting food aid.

Table 11: Coping up mechanism for food insecurity.

\begin{tabular}{|c|c|c|}
\hline Types of Coping Mechanisms & Respondents & Percentage \\
\hline Getting loan & 5 & $4.35 \%$ \\
\hline Sale animals & 13 & $11.30 \%$ \\
\hline Renting own land & 3 & $2.61 \%$ \\
\hline Food aid & 8 & $8.70 \%$ \\
\hline
\end{tabular}

\section{Conclusion and Recommendations}

The main objective of the study was to identify the determinants of household food insecurity and its coping mechanisms in woliso woreda, Southwest Shoa zone. The study used primary and secondary source of data. To achieve this objective the study relied on primary data, which were collected by conducting household's survey from 115 randomly selected households in three selected kebeles of the woreda.

Data were analyzed using both descriptive statistics and econometric method. The descriptive statistic was used to study the demographic, socioeconomic and institution factor in relation to food insecurity status of households and its coping mechanisms in the study area. The econometric method in which probit regression model was specified and estimated was used to analyze the determinants of food insecurity in the study area.

The sample households were classified in to food secure and food insecure groups based on Kcal actually consumed by household during the month, seven day and daily. According to the result the study showed that about 86 (74.8 percent) and 29 (25.2 percent) households were food secure and food insecure respectively [2428]. The binary probit model showed that, ceremonial expense, livestock, dependency ratio, educational level and pesticide use were found to be statistically significant determinants of food insecurity status. Ceremonial expense and dependence ratio were positively related to food insecurity status with the prior expectation in sign at 5 and 1 percent significant level respectively, while livestock, household head education and pesticide use were found to be inversely related with the prior expectation in sign at $5 \%$ probability level of significance.

Socio-economic factors such as low level of income (income constraint), low level of education, low level of access to new technology such as improved seeds, chemical fertilizer, herbicide, pesticide, high expenditure for social ceremonies and celebrations [29]. In addition to this, the weakness of institutional factors also one of the hindered for food self-sufficiency to rural household, such as absence of enough rural financial institutions, poor market integration and problem of land distribution by local leaders were the main challenges of the study area farmers not to have sufficient cereal production to their family members.

Demographic factors such as low family planning and low land holding size compared to family size, due to weakness of rural administration, low rural infrastructure [30,31]. In addition, to this the adaption of new technology such as improved seeds, chemical fertilizer, pesticides are very low due to the reasons of high input price, income constraint, and not given based on the capacity of the farmers.

There is low habit of loan (credit) use due to high interest rate in the study area. As the results of all the above factors, the agricultural productivity is very low in the study area and the households suffered by food insecurity.

During the time of food shortage, the rural households adapt various mechanisms to cope with the problems. Among those getting loan either from their relatives, friends, neighbors or from formal and informal financial institutions, selling of domestic animals for the purpose of purchasing food crops, contracting their own land to rich farmers either by money or by sharing cereals and grains as a contingency [32-35]. In addition to those coping mechanisms, the rural households applied some other coping mechanisms such as selling fire wood and engaged from non-farm activities to generate daily wage. This shows that the most coping mechanisms are important for the temporarily.

\section{Recommendations}

The agricultural sector is the main engine of our economy which contributes much for the future growth of the country. Most of the Ethiopian's population are depends on agricultural sector and their food is from the agricultural production directly or indirectly. 
Therefore, the improved and modernization of agriculture through different measures will enable the country to be self-sufficient in food. Based on the discussion made throughout this paper and observed food insecurity problem in the study area, the following recommendations are forwarded.

a. The government must provide enough rural infrastructure, market information and good administration to the rural area farmers.

b. Discourage the unnecessary expenditure for various ceremonies and celebrations to tackle the household food shortage.

c. Reducing population pressure through family planning program.

d. Protected early marriage and preventive unwanted pregnancy to reduce population.

e. Enhancing the output of the livestock (TUL) through the provision or supply of better veterinary service sector.

f. Expand financial institutions; provide loan (credit), and farming inputs based on the capacity (ability to pay of the farmers with low interest rate.

g. Government must enhance the supply of fertilizer at low price to rural farmers.

h. The regional and federal government must provide access education for farmers.

i. Generally, food insecurity is a multifaceted concept, which cannot be treated in isolation from other causes of poverty. Therefore, efforts geared towards achieving foods security should be addressed to the areas of human skill and infrastructure development.

\section{Acknowledgement}

None.

\section{Conflict of Interest}

No Conflict of Interest.

\section{References}

1. Br Wolday Amaha (2014) Food Insecurity in Ethiopia; policy intervention, EEA, VOL, Addis Ababa Ethiopia.

2. Samuel Taye, Seleyabna Temesgen (2014) towards Ensuring Food Security, Ethiopia Herald Journals reports A.A Ethiopia.

3. USAID (2016) Policy Determination of Food Security. Washington, USA.

4. Reta (2011) Studied cause and consequence of food insecurity in Woliso woreda, Ethiopia by using descriptive analysis

5. Adugna W (2012) Determinants of Livelihood Strategy in Wolaita southern Ethiopia. Agricultural Research and Reviews 1(5): 153-161.

6. HK Haile, ZG Alemu, G Kudhlande (2005) Cause of Household Food Insecurity in Koredegage Peasants Association, Oromia zone, Ethiopiaworking paper.

7. S Feleke, RL Kilmer, C Gladwin (2003) Determinants of Food Security in Southern Ethiopia. pp. 29.
8. Annual Reports of Ethiopian Economy (1999/2000) The Problem and Prospect of Food Security 2nd edition, Ethiopian Economic Association A.A. Ethiopia.

9. Aschalew Feleke (2006) Determinants and Dimensions of Household Food Insecurity in Dire Dawa City, Ethiopia an M.Sc. Thesis presented to the School of Graduate Studies of Alemaya University. Pp 64.

10. Maddala G (1992) Introduction to Econometrics New York, Macmillan.

11. Adekoyo N (2009) Gender and Household Food Security Household level, in Oyo state of Nageria.

12. Agnes Odejide (1996) Food Self-Sufficient in Africa, African political economy.

13. Alazar Shiferaw (2013) New Hope for Ensuring Food Security, the Ethiopian Herald Journal, Addis Ababa, Ethiopia.

14.BARDWW (Bureaus of Agricultural Rural Development of Woliso Woreda, 2017) Woliso, Ethiopia.

15. DPPCO (2017) disaster prevent and preparedness commission Office. Woliso, Ethiopia.

16. Kinfe Abraham (2015) Strategic Response to Food Security, Ethiopian dynamic economic reform, $1^{\text {st }}$ edn, AdissAbeba Ethiopia.

17. Eden M, Negatu R, Y Ansha (2009) The Levels, Determinants and Coping Mechanisms' of Food Insecure Household in Southern Ethiopia. Dray lands cooperation Group, Norway 55: 1-39.

18. EEA (2007) Proceeding of the fifth international conference on Ethiopian economy A.A. Ethiopia.

19. FAO (2003) Special Program for Food Security Expands in Ethiopia Addis Abeba.

20. FDRE (2001) Food Security Strategies of Ethiopia A.A. Ethiopia.

21. Feleke ST, RL Kilmer, CH Gladwin (2003) Determinants of Food Security in Southern Ethiopia at the Household Level Agricultural Economics 33(3): 351-363.

22. Hoddinott J (2001) Method for Rural Development Projects: Food Security in Practice, pp. 118.

23. IFAD (2001) Gender and Household Food Security: A conceptual framework, Rome, Italy.

24. IFPRI (2007-2008) International Food Policy Research Institute.

25. LSRO (1998) Standardized Operational and Estimating Food Security, United State.

26. ML Narasaiah (2015) Food Security: Availability and Access to Food, Market and Agricultural development $1^{\text {st }}$ edn New Delhi India.

27. Mesay Mulugeta (2016) The Ethiopian Journal of Business and Economics (EJBE), A.A Ethiopia. 6(1).

28. MoFED (2010/11) Ethiopia's Progress towards Eradicating Poverty: An Interim Report on Poverty Analysis Study (2010/11). Development Planning and Research Directorate, Ministry of Finance and Economic, Development March 2012, Addis Ababa, 2012.

29. MoFED (1992) Analysis of Household Food Expenditure Pattern in Ethiopia Food and Nutrition unit A.A. Ethiopia.

30. WFP (2013) Fighting Hunger World Wide: Annual Report. Ethiopia.

31.WFP, CSA (2014) 'Comprehensive Food Security and Vulnerability Analysis (CFSVA): Executive Summary. Ethiopia.

32.WFP (world food program) Ethiopia (2012) Special Reports. FAO/ WFPcrop and Food Supply Assement mission to Ethiopia, Addis Abeba.

33. WFS (1996) the State of Food Security in the world. Rome.

34. World Bank (2013) Nutrition, the World Development Indicators, Washington DC, USA.

35. (2017) WWALPB: Woliso woreda Agricultural and Land protection Bureau Woliso, Ethiopia. 